\title{
Pain and life quality within 2 years of spinal cord injury
}

\author{
AG Wagner Anke, AE Stenehjem and J Kvalvik Stanghelle \\ Sunnaas Rehabilitation Hospital, 1450 Nesoddtangen, Norway
}

\begin{abstract}
The prevalence and classification of pain were investigated in 46 patients admitted consecutively with traumatic spinal cord injury to a rehabilitation hospital. All were studied within 2 years of trauma. Forty-six percent experienced pain of moderate-to-severe intensity. The patients with pain were classified into five categories: diffuse pain, segmental pain, root pain, visceral pain and non-neurogenic pain. Most patients experienced more than one type of pain. Pain appeared more intense in the evening than in the morning or at noon. Older age (median 40 years $v s 24$ years) was related to increased prevalence of pain. Significantly more patients with pain $(70 \%)$ than without pain $(24 \%)$ had a case-score on the 20 -item version of the General Health Questionnaire, indicating psychological distress and reduced quality of life. The present study indicates that pain causes emotional distress in addition to the distress associated with the spinal cord injury itself.
\end{abstract}

Keywords: spinal cord injury; pain; classification; life quality; psychological distress

\section{Introduction}

Chronic pain is a major sequela to spinal cord injury. Still, surprisingly little attention is given to this problem from a scientific point of view, and comparative studies are rare. ${ }^{1}$ As there is no agreement about either classification of pain or the prevalence of different pain types $^{2}$ this investigation further examined the prevalence and classification of pain in patients with spinal cord injury. In addition, we studied eventual predictors for the development of pain, and asked whether pain influenced the quality of life in traumatic spinal cord injury patients.

\section{Material and methods}

From February 1992 to October 199346 patients with traumatic spinal cord injury, consecutively admitted to Sunnaas Rehabilitation Hospital, were included in the study. Thirty six men and ten women, with median age 32 years (range 15-76 years), were studied median 32 weeks (range 14-104 weeks) after injury. Most patients ( $n=40,87 \%$ ) were examined during the last weeks of their primary rehabilitation, and all patients underwent the investigation less than 2 years after injury.

A neurological examination was performed in all patients. Determinations of motor and sensory injury levels and completeness of injury were made according to the American Spinal Injury Association criteria. ${ }^{3}$ Pertinent data included sex, age, and level and completeness of spinal cord injury.

Pain intensity during the last week was rated by the

Correspondence: AGW Anke, Department of Physical Medicine and Rehabilitation, University Hospital of Troms $\varnothing$, 9038 Troms $\varnothing$, Norway patients on a six-point scale (none, slight, moderate, severe, very severe and unbearable pain). For simplification the ratings were divided into two categories: none or slight pain versus moderate, severe, very severe and unbearable pain. We defined the patients in the last category as having clinically significant pain. These patients underwent a pain interview, including a pain drawing, assessment of the duration of pain, and assessment of pain intensity. Pain intensity was assessed on a visual analog scale (VAS) from $0-10 \mathrm{~cm}$ three times daily for between 2 and 7 days.

\section{Original pain classification}

Our registrations were based upon the following description of different types of pain in spinal cord injured patients by Christensen and Jensen: ${ }^{4}$

Root pain. Asymmetric, segmental localised pain, sharp, with paroxysmal occurrence.

Segmental pain. Often bilateral symmetric occurrence within two or three spinal segments of the zone of injury, spontaneous, burning character, hyperalgesic border reaction. (Clinicians often call this phenomenon dysaesthesia).

Diffuse pain or phantom body pain. Multifarious, characterised by constant, diffuse, generalised, burning, pricking, tingling pain in paralytic and anaesthetic areas.

Visceral pain. Deep, diffuse, spastic pain in central abdomen. The attacks can be provoked by bladder or bowel distension. 
Dysaesthesia. Abnormal sensation occurring spontaneously or by provocation in dermatomes at or below the medullary lesion.

Allodynia. Often synonymous with dysaesthesia, but always unpleasant and initiated by non-painful stimuli.

In addition we noted the occurrence of nonneurogenic pain such as musculoskeletal pain or headache.

\section{Quality of life}

Subjective wellbeing, psychological distress or quality of life was studied by the 20 -item version of the General Health Questionnaire (GHQ 20), a self-administered questionnaire. $^{5}$ The respondents were requested to compare their current status with their normal situation on a four-point scale ranging from 'less than usual' to 'much more than usual' ('normal situation' was defined by the patients themselves). The answers on each item were scored as a 'Likert scale' with weights assigned to each position $(0-1-2-3)$. This gave a possible range for the total GHQ 20 score of $0-60$. Malt ${ }^{5}$ proposed using a cut-off point between 23 and 24; thus in this study a score of 24 or higher was called a GHQ-case score.

\section{Statistics}

For comparisons of groups of data simple crosstabulation was performed (Fisher's exact test), while the Mann-Whitney non-parametric two sample test was used to analyse differences in medians. We considered $P$ values $<0.05$ statistically significant.

\section{Results}

Pain prevalence and pain classification

Twenty one $(46 \%)$ of the patients reported clinically significant pain according to our definition. As shown in Table 1 (result A), these patients suffered from 51 types of pain, which means that most patients experienced more than one pain type. In five patients diffuse

Table 1 Prevalence of pain in 46 patients with traumatic spinal cord injury. Result A gives the numbers of different pain types in 21 patients with pain after spinal cord injury. In $\mathrm{B}$, as one patient often has more than one pain type, the patients are classified into mutually exclusive pain groups. If a patient suffered from more than one pain type, diffuse pain took precedence over segmental pain, segmental pain over root pain, and root pain over musculoskeletal pain. Dysaesthesia and allodynia were included in one of the other neurogenic pain types

\begin{tabular}{lrr}
\hline & $A$ & $B$ \\
\hline Diffuse pain (including visceral pain) & 8 & 8 \\
Segmental pain & 17 & 12 \\
Root pain & 2 & 0 \\
Dysaesthesia/allodynia & 12 & - \\
Musculoskeletal pain & 12 & 1 \\
All & 51 & 21 \\
\hline
\end{tabular}

pain and segmental pain occurred simultaneously, while one patient experienced the combination of diffuse pain, segmental pain and root pain. In another patient root pain prevailed simultaneously with segmental pain. Dysaesthesia and allodynia invariable occurred concurrently with segmental pain or diffuse pain, and 11 out of 12 patients with musculoskeletal pain in addition suffered fron neurogenic pain.

As dysaesthesia and allodynia always occurred contemporary with segmental pain or diffuse pain, we preferred to include dysaesthesia and allodynia as part of the picture in one of these neurogenic pain types. The classification suggested by Christensen and Jensen ${ }^{4}$ was, in our opinion, too detailed. We chose to classify the patients according to Figure 1.

For the purpose of classification of patients into mutually exclusive pain groups, if a patient experienced two or more types of pain, diffuse pain took precedence over segmental pain, segmental pain over root pain and root pain over non-neurogenic pain. The paroxysmal visceral pain was difficult to isolate from other types of pain, and was generally included together with diffuse
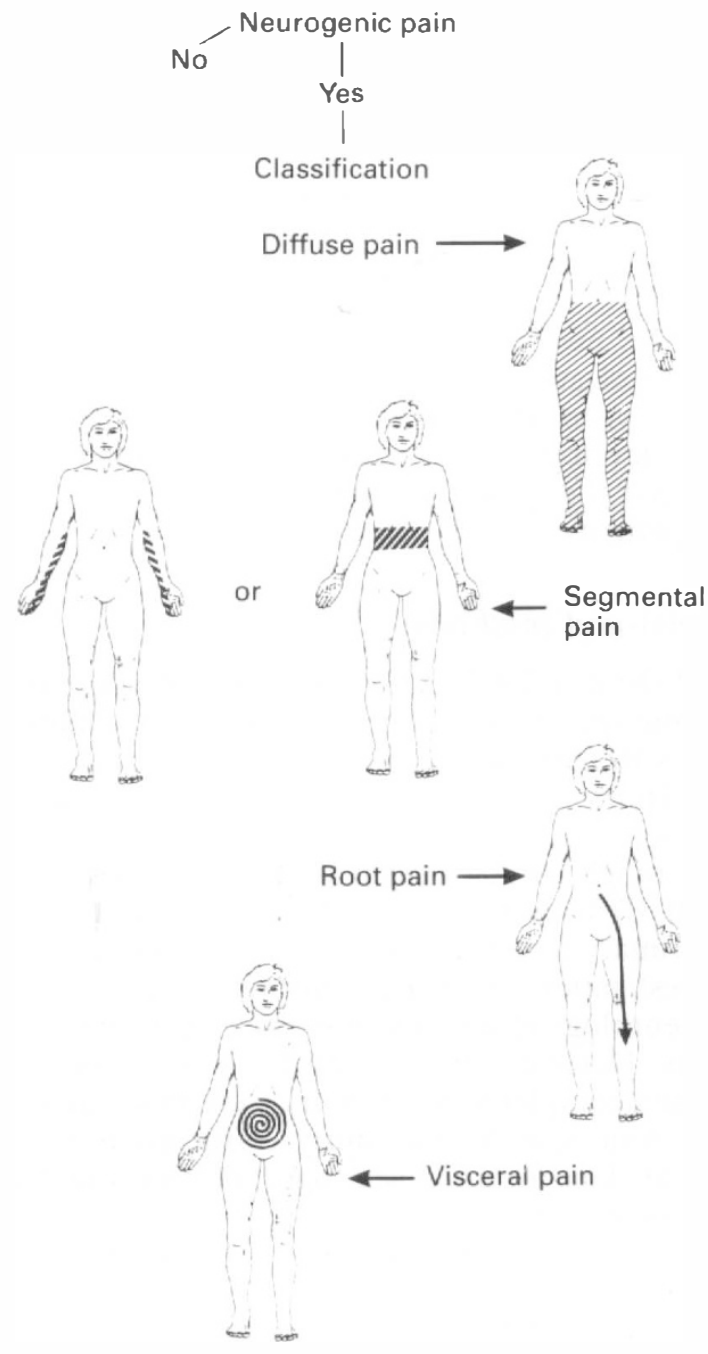

Figure 1 Classification of neurogenic pain in patients with spinal cord injury 
pain. In our study, this main classification gave three categories: diffuse pain in eight patients $(17 \%)$, segmental pain in 12 patients $(26 \%)$ and musculoskeletal pain only in one patient $(2 \%)$ (Table 1 , result B). The one patient with musculoskeletal pain only suffered from lumbago which started 4 months post injury.

\section{Pain duration and variation during the day}

At the time of the investigation the patients had suffered from pain for a median of 23 weeks (range 3-66 weeks). Among a total of 20 patients with neurogenic pain, seven patients experienced immediate onset of pain after the injury, nine patients developed pain within 3 months following injury, and the pain was initiated within 6 months after injury in all 20 patients. The neurogenic pain was constant in nature and occurred every day in most of the patients $(n=16)$, while four patients experienced days without pain sporadically.

Fifteen out of 20 patients with neurogenic pain rated their subjective experience of pain intensity three times daily on a visual analog scale. Table 2 demonstrates that pain in these patients was more intense in the evening than in the morning or at noon.

\section{Predictors}

The patients who reported pain were older (median 40 years) than the patients without pain (median 24 years) $(P=0.034$, Mann-Whitney test). Table 3 shows the relations between pain and sex, pain and spinal cord lesion level, and pain and Frankel classification, respec- tively, indicating no increased risk for developing pain in either of the subgroups studied.

\section{Quality of life}

The scores on GHQ 20 were pathological in 21 patients $(46 \%)$, indicating psychological distress or reduced life quality. It was statistically significant that more patients with pain $(70 \%)$ than patients without pain $(24 \%)$ had a pathological score on GHQ 20 (Table 4).

\section{Discussion}

The principal findings in this investigation of a consecutive series of patients with traumatic spinal cord injuries were that $46 \%$ developed pain of moderate or more severe intensity, all within 6 months after injury, and that the occurrence of pain clearly influenced the patient's quality of life in a negative way. A possible

Table 4 Pain intensity and rating of subjective wellbeing (quality of life) according to the General Health Questionnaire (GHQ 20) in 46 patients with spinal cord injury. Number of patients in each group are given

\begin{tabular}{lcc}
\hline & $\begin{array}{c}\text { GHQ-normal } \\
n\end{array}$ & $\begin{array}{c}G H Q \text {-case } \\
n\end{array}$ \\
\hline $\begin{array}{l}\text { No or weak pain } \\
\begin{array}{l}\text { Moderate, severe or } \\
\text { unbearable pain }\end{array}\end{array}$ & 19 & 6 \\
\hline
\end{tabular}

$P=0.003$ (Fisher's exact test)

Table 2 Pain intensity rated three times daily in 15 patients with neurogenic pain after spinal cord injury. Pain intensity was measured on a visual analog scale $0-10 \mathrm{~cm}$

\begin{tabular}{lccc}
\hline Pain type & \multicolumn{2}{c}{ Visual analog scale (median and range) } & Evening $(8 \mathrm{pm})$ \\
\cline { 2 - 4 } & Morning $(8 \mathrm{am})$ & Noon $(2 \mathrm{pm})$ & $4.1(2.9-8.4)$ \\
Diffuse pain $(n=6)$ & $2.3(0.9-3.7)$ & $3.3(0.8-5.3)$ & $5.2(3.0-8.7)$ \\
Segmental pain $(n=9)$ & $3.0(0-8.8)$ & $3.9(1.7-5.4)$ & $5.1(2.9-8.7)^{*}$ \\
Neurogenic pain, total $(n=15)$ & $2.3(0-8.8)$ & $3.4(0.8-5.4)$ & \\
\hline
\end{tabular}

*Statistically significant higher values in the evening compared to the values in the morning $(P=0.001)$ or at noon $(P=0.010$, Mann-Whitney test $)$

Table 3 The relation between pain and sex, pain and spinal cord lesion level, and pain and Frankel classification, respectively, in 46 patients with spinal cord injury

\begin{tabular}{|c|c|c|c|}
\hline & $\begin{array}{c}\text { Number of patients } \\
n\end{array}$ & $\begin{array}{c}\text { Patients with pain } \\
n(\%)\end{array}$ & $\begin{array}{c}P \text {-value } \\
\text { (Fisher's exact test) }\end{array}$ \\
\hline $\begin{array}{l}\text { Men } \\
\text { Women }\end{array}$ & $\begin{array}{l}36 \\
10\end{array}$ & $\begin{array}{r}17(47 \%) \\
4(40 \%)\end{array}$ & $P=1.000$ \\
\hline $\begin{array}{l}\text { Tetraplegic patients } \\
\text { Paraplegic patients }\end{array}$ & $\begin{array}{l}23 \\
23\end{array}$ & $\begin{array}{l}11(48 \%) \\
10(43 \%)\end{array}$ & $P=1.000$ \\
\hline $\begin{array}{l}\text { Frankel A } \\
\text { Frankel B-E }\end{array}$ & $\begin{array}{l}18 \\
28\end{array}$ & $\begin{array}{l}10(56 \%) \\
11(39 \%)\end{array}$ & $P=0.597$ \\
\hline
\end{tabular}


classification of pain into five main categories was suggested: diffuse pain, segmental pain, root pain, visceral pain and non-neurogenic pain (ie musculoskeletal, headache) (Figure 1). A surprising number of patients reported experiencing more than one type of pain.

Estimates of moderate-to-severe prevalence of pain in spinal cord injury patients ranges from 27 to $77 \%{ }^{6}$ The prevalence of pain in the present study $(46 \%)$ is comparable with the findings of Britell ${ }^{7}(42 \%)$, but lower than the prevalence reported by Woolsey ${ }^{8}(67 \%)$ or $\operatorname{Rose}^{9}(69 \%)$. These discrepancies can be explained by the definitions of pain, as the latter studies also included mild pain in their results. The differences, however, could also partly be caused by an increased prevalence of pain with time after injury. This could be an area of further studies.

The generalised, diffuse dysaesthetic pain experienced in paralytic and anaesthetic areas has been given many names: dysaesthetic pain syndrome, ${ }^{10}$ phantom sensation, ${ }^{11}$ burning pain below site of injury, ${ }^{8}$ spinal cord pain, ${ }^{12}$ central dysaesthesia syndrome, ${ }^{13}$ central spinal cord dysaesthesia or 'deafferentation' pain, ${ }^{6}$ and phantom body pain. ${ }^{14} \mathrm{We}$ chose the name diffuse pain because it is descriptive of the phenomenon.

In contradiction to earlier investigations we found that the dysaesthetic pain localised within two to three spinal segments of the zone of injury, in our investigation called segmental pain, was the most common pain type. In fact, $26 \%$ of the spinal cord injury patients were classified in this category, while only $17 \%$ reported to suffer from diffuse pain. Other authors have claimed the diffuse pain (also called dysaesthetic pain syndrome) to be most frequent after spinal cord injury. ${ }^{1,6,10}$ In contrast to others, ${ }^{6,12}$ we found it natural to define the pain type resembling nerve root pain; sharp, asymmetric and paroxysmal, as one separate type of pain, although like the segmental pain, it was localised to spinal segments in the injury zone. This is, in our opinion, in accordance with clinical practice, as root like pain is usually treated with carbamazepine or other anticonvulsants. ${ }^{6}$

Our investigation also indicated that pain appeared more intense in the evening than at noon or in the morning. This result is interesting from a therapeutic point of view, and should be taken into consideration when treatment is planned. Also, clinicians probably seldom examine their patients in the evening, and could therefore fail to recognise the problem adequately.

To our knowledge, there is no previous report on increased prevalence of pain in patients who were injured at a higher age compared with the prevalence in patients who were injured at younger age. In this investigation all patients were included within two years post injury, and the group with pain was significantly older (40 years) than the patients without pain (24 years).

In contrast to our findings, Davidoff et al ${ }^{10}$ demonstrated an increased risk of pain experience in paraplegic versus tetraplegic patients, and in patients with sensory incomplete versus sensory complete spinal cord lesions. These divergent results could be explained by the inclusion criteria, as Davidoff et al ${ }^{10}$ included only patients with 'dysaesthetic pain syndrome', ie patients with diffuse pain, which probably represents a specific subgroup of patients with pain after spinal cord injury. However, Nepomuceno ${ }^{11}$ also noted a lower incidence of severe pain among those having cervical lesions and a higher one in patients with lumbosacral lesions. As others $^{6,14}$ have discussed, the cauda equina lesions could represent another subgroup, but our material covered too small a sample to confirm or contradict this clinical possibility. Our results were in accordance with Summers et al, ${ }^{15}$ who found no association between pain severity and level or completeness of injury.

A major goal of this study was to include aspects of life quality in relation to chronic pain and spinal cord injury. The General Health Questionnaire (GHQ) has been found to be sensitive to changes in psychological status following distressed events, and since somatic symptoms are not included, the 20 -item version is particularly recommended to study the psychological status in physically injured patients. ${ }^{5}$ As many as $70 \%$ of the spinal cord injured subjects with pain had a pathological score on the General Health Questionnaire, while the spinal cord injured subjects without pain had no higher prevalence of psychological distress $(24 \%)$ than a normal population sample. ${ }^{16}$ There is no reason to believe that higher age per se gives lower quality of life, as a previous study demonstrated that levels of global life-satisfaction were not age dependent. ${ }^{17}$ Also, the finding of a high per cent of pathological score on GHQ in the patients suffering from pain is in accordance with Lundqvist et al, ${ }^{18}$ who demonstrated severe pain to be the only complication that related to lower quality of life in subjects with spinal cord injury. Our clinical impression that pain negatively influences the ability to cope with a severe impairment, even in a relatively early stage after injury, was confirmed in this study. Moreover, in accordance with Summers et al,$^{15}$ our results indicate that pain causes psychological distress and reduced quality of life, a significant emotional distress in addition to the distress associated with the spinal cord injury itself.

\section{References}

1 Mariano AJ. Chronic pain and spinal cord injury. Review article. Clin J Pain 1992; 8: 87-92.

2 Richards JS. Chronic pain and spinal cord injury: review and comment. Clin J Pain 1992; 8: 119-122.

3 Ditunmo JF, Young W, Donovan WH, Creasey G. The International Standards Booklet for Neurological and Functional Classification of Spinal Cord Injury. Paraplegia 1994; 32: 70-80.

4 Christensen FL, Jensen TS. Disturbances of sensation and pain in patients with spinal cord lesions (Danish). Ugeskr Lager 1991; 153: 3466-9.

5 Malt UF. The validity of the General Health Questionnaire in a sample of accidentally injured adults. Acta Psychiatr Scand Suppl 335 1989; 80: 103-112.

6 Britell CW, Mariano AJ. Chronic pain in spinal cord injury. Physical Medicine and Rehabilitation: State of the Art Reviews. Philadelphia, Hanley \& Belfus Inc: Philadelphia, 1991, pp $71-81$. 
7 Britell CW, Umlauf R, Loehr J, DeLisa JA. Problem survey in an SCI outpatient clinic population: A case of multifaceted, ongoing care. Arch Phys Med Rehabil 1986; 67: 654.

8 Woolsey RM. Chronic pain following spinal cord injury. J Am Paraplegia Soc 1986; 9: 39-41.

9 Rose M, Robinson JE, Ells P, Cole JD. Pain following spinal cord injury: results from a postal survey. Pain 1988; 34: 101-102.

10 Davidoff $\mathrm{G}$ et al. Function-limiting dysaesthetic pain syndrome among traumatic spinal cord injury patients: a cross-sectional study. Pain 1987; 29: 39-48.

11 Nepomuceno $\mathrm{C}$ et al. Pain in patients with spinal cord injury. Arch Phys Med Rehabil 1979; 60: 605-609.

12 Donovan WH, Dimitrijevic MR, Dahm L, Dimitrijevic M. Neurophysiological approaches to chronic pain following spinal cord injury. Paraplegia 1982; 20: 135-146.
13 Beric A, Dimitrijevic MR, Lindblom U Central dysaesthesia syndrome in spinal cord injury patients. Pain 1988; 34: 109-116.

14 Melzack R, Loeser JD. Phantom body pain in paraplegics: evidence for a central 'pattern generating mechanism' for pain. Review article. Pain 1978; 4: 195-210.

15 Summers JD et al. Psychosocial factors in chronic spinal cord injury pain. Pain 1991; 47: 183-189.

16 Malt UF, Blikra G, Høivik. The three-year biopsychosocial outcome of 551 hospitalized accidentally injured adults. Acta Psychiatr Scand Suppl 335 1989; 80: 84-93.

17 Fugl-Meyer AR, Bränholm I-B, Fugl-Meyer KS. Happiness and domain-specific life satisfaction in adult northern Swedes. Clin Rehabil 1991; 5: 25-33.

18 Lundqvist $\mathrm{C}$ et al. Spinal cord injuries. Clinical, functional and emotional status. Spine 1991; 16: 78-83. 